\title{
Characterization of Contaminant Transport by Gravity, Capillarity and Barometric Pumping in Heterogeneous Vadose Zones
}

C. R. Carrigan, S. A. Martins, A. L. Ramirez, W. D. Daily, G. B. Hudson, D. Ralston, B. Ekwurzel

February 27, 2001

U.S. Department of Energy

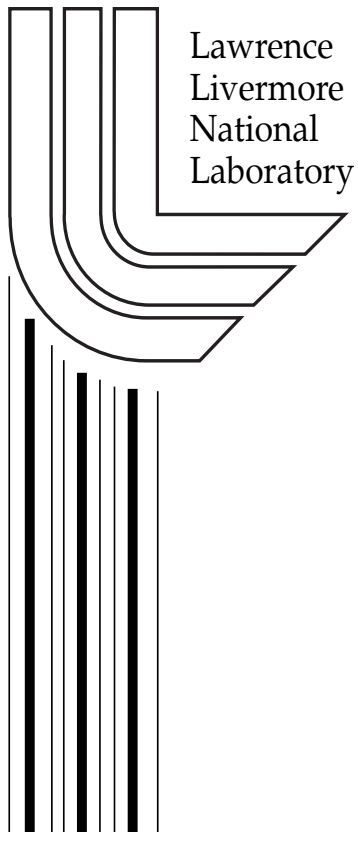




\section{DISCLAIMER}

This document was prepared as an account of work sponsored by an agency of the United States Government. Neither the United States Government nor the University of California nor any of their employees, makes any warranty, express or implied, or assumes any legal liability or responsibility for the accuracy, completeness, or usefulness of any information, apparatus, product, or process disclosed, or represents that its use would not infringe privately owned rights. Reference herein to any specific commercial product, process, or service by trade name, trademark, manufacturer, or otherwise, does not necessarily constitute or imply its endorsement, recommendation, or favoring by the United States Government or the University of California. The views and opinions of authors expressed herein do not necessarily state or reflect those of the United States Government or the University of California, and shall not be used for advertising or product endorsement purposes.

This is a preprint of a paper intended for publication in a journal or proceedings. Since changes may be made before publication, this preprint is made available with the understanding that it will not be cited or reproduced without the permission of the author.

This work was performed under the auspices of the United States Department of Energy by the University of California, Lawrence Livermore National Laboratory under contract No. W-7405-Eng-48.

This report has been reproduced directly from the best available copy.

Available electronically at http://www.doc.gov/bridge

Available for a processing fee to U.S. Department of Energy

And its contractors in paper from

U.S. Department of Energy

Office of Scientific and Technical Information

P.O. Box 62

Oak Ridge, TN 37831-0062

Telephone: (865) 576-8401

Facsimile: (865) 576-5728

E-mail: reports@adonis.osti.gov

Available for the sale to the public from

U.S. Department of Commerce

National Technical Information Service

5285 Port Royal Road

Springfield, VA 22161

Telephone: (800) 553-6847

Facsimile: (703) 605-6900

E-mail: orders@ntis.fedworld.gov

Online ordering: http://www.ntis.gov/ordering.htm

Or

Lawrence Livermore National Laboratory

Technical Information Department's Digital Library

http://www.llnl.gov/tid/Library.html 


\title{
FINAL REPORT
}

U.S. Department of Energy

\section{CHARACTERIZATION OF CONTAMINANT TRANSPORT BY GRAVITY, CAPILLARITY\& BAROMETRIC PUMPING IN HETEROGENEOUS VADOSE ZONES}

\author{
Principal Investigator: Charles R. Carrigan \\ Institution: Lawrence Livermore National Laboratory \\ Collaborators (co-investigators): Stan Martins, Abe Ramirez,

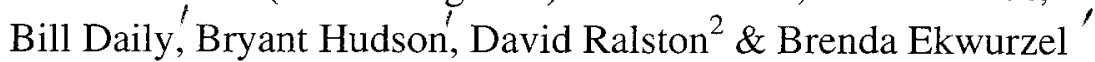 \\ (1) \\ Institutions: Lawrence Livermore National Laboratory \\ ${ }^{2}$ Defense Nuclear Facilities Safety Board
}

Project Number: 54950

Grant Number: not applicable (DOE Lab; TTP \#SF2-7-SP-22, Task C)

Grant Project Officers: not applicable (DOE Lab; Technical Program Officer Paul Ko, DOE Oakland Field Office)

Project Duration: 10/01/96 to 9/30/99

LLNL report number UCRL-ID-XXXXXX, 2-27-2001 


\section{Table of Contents}

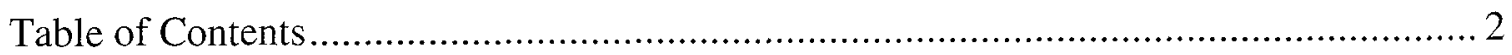

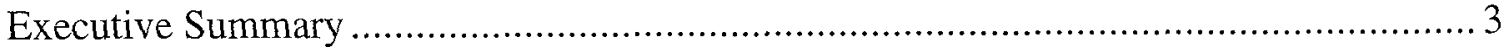

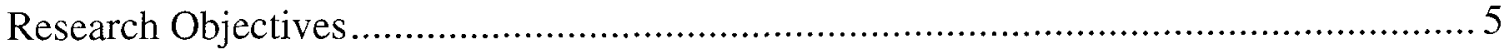

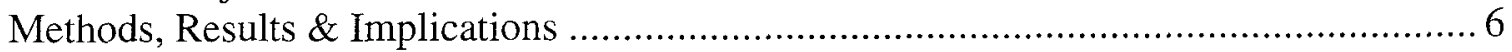

The Vadose Zone Observatory ............................................................. 6

Monitoring Liquid-Phase, Colloidal And Gas-Phase Infiltration Events ..................... 6

Modeling: The Framework For Field Observations ….................................... 8

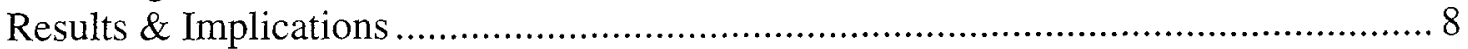

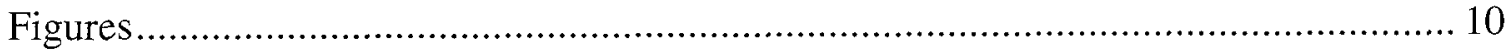

Relevance, Impact and Technology Transfer ................................................ 15

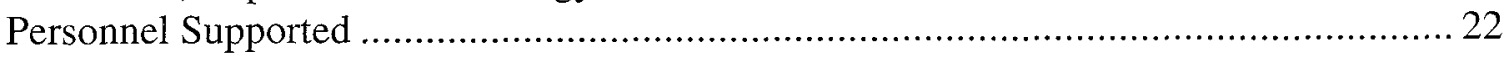

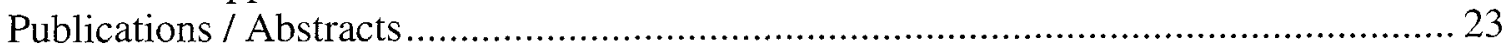

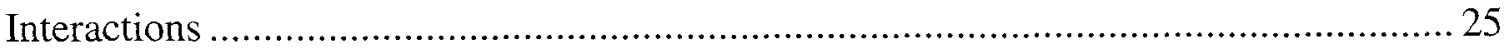

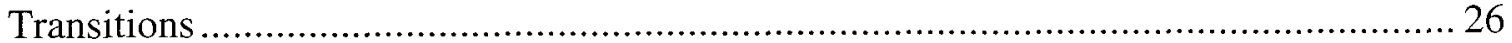

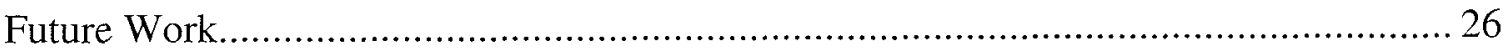

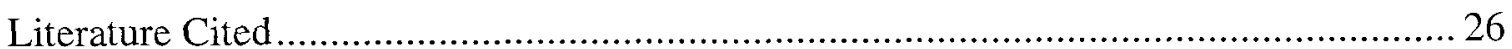




\section{Executive Summary}

This final report summarizes the work and accomplishments of our three-year project. We have pursued the concept of a Vadose-Zone Observatory (VZO) to provide the field laboratory necessary for carrying out the experiments required to achieve the goals of this research. Our approach has been (1) to carry out plume release experiments at a VZO allowing the acquisition of several different kinds of raw data that (2) are analyzed and evaluated with the aid of highly detailed, diagnostic numerical models.

The key feature of the VZO constructed at Lawrence Livermore National Laboratory (LLNL) is the variety of plume-tracking techniques that can be used at a single location. Electric resistance tomography (ERT) uses vertical arrays of electrodes across the vadose zone that can monitor electrical resistance changes in the soil as a plume moves downward to the water table. These resistance changes can be used to provide "snapshots" of the progress of the plume. Additionally, monitoring wells have been completed at multiple levels in the vicinity of a central infiltration site. Sensors emplaced at different levels include electrically conducting gypsum blocks for detecting saturation changes, thermistors for monitoring temperature changes and pressure transducers for observing barometric changes at different levels in the vadose regime. The data from these sensors are providing important information about the state of the gas- and liquidphase dynamics of the infiltration process. Similarly, access ports at different levels have been used to supply gas-phase samples while lysimeters yield liquid-phase samples. Studies involving gas-phase tracers were carried out at LLNL and at an Orange County Water District site in southern California to evaluate the time-dependent chemical signature of a plume that was spiked with an array of dissolved noble-gas tracers. Our work also correlate chemical signatures with those of the above-mentioned sensors that track the physical changes in the vadose zone.

From the VZO at the LLNL site and from 3-D diagnostic simulations of our very first tracer-spiked plume infiltration event, we produced a much better understanding of the implications of soil heterogeneity for unsaturated zone contaminant transport at DOE sites. Even though the LLNL VZO site is considered to be hydrologically "tight" owing to the low permeability of the clays and silts that dominate the soil formations there, we find that saturation increases resulting from a near-surface "leak" reach the water table across the 20-meter-thick vadose zone in only tens of hours. This rapid transport at the site cannot be accurately simulated by layered models that derive their hydrologic properties from borehole-soil samples. In the LLNL vadose zone, layered infiltration models clearly underpredict of the rate of contaminant infiltration to the water table. Chemical transport simulations based on layered models of the Hanford vadose zone also appear to drastically underpredict contaminant migration. Furthermore, only simulations assuming a heterogeneous regime "threaded" by extremely high-permeability pathways can explain the rapid increase in saturation observed with ERT near the water table. Three-dimensional predictive models of a hypothetical tritiated water leak that are based on the above mentioned VZO infiltration-experiment diagnostic models were run. Tritiated water is an excellent conservative tracer and the infiltration simulations predict, in very good agreement with VZO experiments, that a continuous hypothetical tritium 
release (2-3 liters/min) would be expected to reach the water table at significant concentrations within days. The numerical model suggests that this arrival time is determined by the amount of time required, infiltrating liquid at a given rate, to flush one pore volume in the soil between the infiltration point and the water table. Another infiltration event monitored by ERT demonstrated that infiltration could occur even more rapidly (within hours) as a result of apparent "fastpaths" in the inhomogeneous soil regime. Because heterogeneity and "fast paths" are so important for understanding the transport of contaminants to the water table and such pathways are inherently threedimensional, one- and even two-dimensional models of layered soils, as have sometimes been used at Hanford, are likely to be inadequate for evaluating vadose zone transport processes. Another concern highlighted by this work having to do with earlier models of contaminant transport at DOE sites is that the soils responsible for fastpaths tend to be absent or badly underrepresented in drill-core samples taken at the site that is to be modeled. This is certainly the case for the VZO site in Livermore and apparently the case at the Hanford FX tank farms. A major conclusion of this project is that it is extremely difficult if not impossible to estimate realistic vadose zone infiltration rates of contamination assuming hydrogeologic models that are based entirely upon hydrologic properties determined from borehole-soil samples. Furthermore, models based on drillcore samples tend to underestimate infiltration rates at contaminated sites. To meaningfully estimate the contaminant migration rates and fluxes to the water table at a site, heavily monitored infiltration test events, as performed at the VZO, are necessary. It is likely that contaminant transport under the mixed-waste tanks at Hanford, for example, could be better understood with the aid of dynamic characterization experiments and diagnostic modeling similar to that carried out for the LLNL VZO site. 


\section{Research Objectives}

It is often hoped that the vadose zone will serve as a barrier to the downward transport of contaminants to the water table. Unfortunately, both the degree to which this is true and the conditions under which the vadose zone either functions or fails as a barrier to different kinds of ground water contamination are often not well known. Experiments of intermediate scale (e.g., somewhere between bench-scale experiments at one extreme and field scale experiments at the other involving surface features such as a quarry or small lake) offer the opportunity to investigate contaminant transport issues in at least a semicontrolled environment to better determine and quantify the important physical and chemical processes associated with contaminant infiltration across the vadose zone.

The intent of this research program is to obtain an improved understanding of vadose zone characteristics and how they affect transport processes and to develop field and modeling techniques required to characterize contaminant transport in the unsaturated zone at DOE sites. For surface spills and near-surface leaks of chemicals, the vadose zone may well become a long-term source of contamination for the underlying water table. Transport of contaminants can occur in both the liquid and gas phases of the unsaturated zone. This transport occurs naturally as a result of diffusion, buoyancy forces (gravity), capillarity and barometric pressure variations. In some cases transport can be enhanced by anisotropies present in hydrologic regimes. This is particularly true for gas-phase transport, which may be subject to vertical pumping resulting from atmospheric pressure changes. For liquid-phase flows, heterogeneity may enhance the downward transport of contaminants to the water table depending on soil properties and the scale of the surface spill or near-surface leak. Characterization techniques based upon staged infiltration events are far more likely to yield a better understanding of the potential for contaminant transport at a specific site than methods depending solely on hydrologic properties derived from borehole samples. Such dynamic-characterization techniques can be useful for evaluating sites where contamination presently exists as well as for providing an objective basis to evaluate the efficacy of proposed as well as implemented clean-up technologies. The real-time monitoring of subsurface infiltration that may occur during clean-up of tank waste and the mobility of contaminants beneath the Hanford storage tanks during sluicing operations is one example of how techniques developed in this effort can be applied to current remediation problems. In the future, such dynamiccharacterization methods might also be used as part of the site-characterization process for determining suitable locations of new DOE facilities that have the potential of introducing contamination into the vadose zone. 


\section{Methods, Results \& Implications}

During the course of this project we developed the concept of elucidating subsurface flow and transport on the field scale by carrying out highly monitored infiltration experiments at a well-characterized site. The infiltration monitoring techniques range from electric resistance imaging (ERT) which gives volumetric information to standard hydrologic point measurements which complement the volumetric imaging observations. Because the observations obtained using different techniques are often not directly comparable, we used detailed numerical simulations as the backbone of our effort to interpret the results of our experiments.

\section{The Vadose Zone Observatory}

The Vadose Zone Observatory (VZO) at Lawrence Livermore National Laboratory is an example of an intermediate scale facility that is well characterized by field-scale standards and allows a high degree of monitoring of infiltration events. The facility utilizes a variety of monitoring methods to track controlled infiltration experiments. The unsaturated regime at the site is approximately 60-70 feet in thickness and consists of silt, silty-sand and silty-gravel deposits. The observatory consists of almost twenty instrumented boreholes and monitoring wells which traverse the 70-foot unsaturated zone including eight wells containing electric resistance tomography (ERT) arrays and four boreholes with multilevel gas-sampling ports, soil temperature sensors, gypsum blocks, tensiometers and lysimeters (Fig. 1). Several multichannel data loggers continuously store information about surface barometric pressure, subsurface gas-phase pressure, subsurface temperature, capillarity and water-table levels that is downloaded into portable computers for analysis. The facility is ideal for carrying out infiltration experiments designed to elucidate how vadose zone characteristics such as preferential pathways, heterogeneities, multiple phases of flow and relative permeabilities influence the transport of contamination in liquid, gas and colloidal phases to the water table. Using the capabilities of the VZO, we can continuously monitor the progress of an infiltration event. In addition, we can also directly take samples of moisture and gases for analysis at many different depths in the vadose zone as well as from the underlying water table. The ability to sample is critical to our infiltration experiments, which include gas- and liquidphase tracers and tagged particles simulating colloids.

\section{Monitoring Liquid-Phase, Colloidal And Gas-Phase Infiltration Events}

To date a number of infiltration events have simulated leaks from tanks or subsurface pipes such as might have occurred beneath the single-walled tanks at Hanford. Either the flow rate or head are controllable from such near-surface point sources. Typical experiments involve the release of 1500 to 80,000 liters of water with typical zero-head injection rates of 2-3 liters/min. The ERT arrays measure electrical conductivity changes resulting from plume-induced chemical changes to the ground water as well as saturation changes. Figure 2 illustrates a typical sequence of ERT images obtained from an early infiltration event (Carrigan et al., 1998). The 3-D images obtained from inversion of the conductivity measurements of the soil bounded by the vertical electrode arrays show 
structure corresponding to electrical conductivity increases down to the water table. In addition to the vadose zone conductivity enhancements associated with saturation changes, tensiometers detect saturation increases throughout the whole vadose regime. Further, both liquid- and gas-phase tracers have been used to track the downward chemical progression of the plume (Ekwurzel et al., 1999) allowing an interesting comparison to be made with the ERT results.

Simulations of infiltration at the site assuming a multi-layered-soil (i.e., 2-D) structure with hydrologic properties determined from lab tests on soil cores suggest that the vadose zone will function as a formidable barrier to contamination of the water table by a nearsurface leak. However, the ERT results show that saturation changes occur down to the water table within hours. Similar results are obtained from gypsum-block tensiometers placed at different levels in a monitoring well near the central infiltration well. A 3-D heterogeneous model (Fig. 3) with high-permeability pathways more closely fits the observations of rapid saturation change down to the water table than the layered model mentioned above (Carrigan et al., 1998). On the other hand, the results of our attempts to track the migration of chemical tracers across the vadose zone show that a significant time lag ( one month) exists between the detection of saturation changes near the water table and the detectable arrival of the tracers at the water table. During this interim period, water was infiltrated periodically until approximately one pore volume had been flushed through the vadose zone. The observed amount of infiltration required for large amounts of tracer to arrive at the water table is in excellent agreement with our numerical simulations (Fig. 3). We attribute this time-lag between the detection of saturation and chemical changes near the water table to be largely a result of displacement and dilution effects. The one observed exception to the displacement-dilution model of contaminant transport to the water table is the observation that a small amount of tracer $(8 \%$ of the concentration change observed later) reached the water table within hours of a 1500 liter infiltration event (Fig. 4). Such an observation can only be explained hydrologically as a fastpath or preferential pathway capturing a small portion of the injected tracer-laden water and channeling it directly to the saturated zone. ERT observations at the VZO support this view since on at least one occasion, imaging indicated that injected, highly conductive, salt water reached the water table only a few hours after the start of injection (Fig 5).

Colloidal transport represents one possible mechanism for the migration of contamination across the vadose zone. The saturated zone is known to readily permit the transport of colloids in a fractured medium subject to the appropriate chemical conditions (McCarthy et al., 1998). At the VZO, a preliminary and ongoing experiment to test the ability of the vadose zone to permit the transport of micron-sized colloids (simulated by micron-size microspheres tagged with fluorescent dye) has not resulted in the detection of these particles at the water table or at any monitoring level in the unsaturated regime to date. During this infiltration experiment, we removed the flexible liners in several of the wells surrounding the central infiltration well and examined the borehole walls for evidence of ground water seepage. After days of infiltration, there was no evidence of seepage into the boreholes or flow along desiccation cracks that intersect the boreholes. The lack of 
seepage in boreholes or in any observable cracks in the vadose zone may have significant implications for the prevention of contaminant migration by colloidal transport.

Transport by the gas phase represents another potential mode by which contaminants can be spread throughout the vadose zone and ultimately reach the underlying water table. In addition to spreading contamination, movement of the gas phase can also influence estimates of contaminant inventories that are based upon gas sampling at different levels in a monitoring well. We have considered the role of gas-phase transport in the vadose zone at our facility. Despite the dominating volume of nearly saturated silty soils at the site, some combination of diffusion and barometric pumping appears to have dispersed tracer gases both vertically and horizontally over the site in a period of months (Carrigan et al., 1998). Using the NUFT multiphase flow-and-transport program developed at LLNL (Nitao, 1995), we evaluated the role of barometric pumping and diffusion upon gas-phase transport in a variety of subsurface soil environments with and without fractures (Ralston et al., 1999, 2001).

\section{Modeling: The Framework For Field Observations}

The different monitoring techniques employed at the VZO produce very different "snapshots" of an infiltration event. Numerically modeling these events is an important part of understanding or reconciling the results obtained from the different monitoring methods. Another way of viewing modeling is that it provides a quantitative framework that can connect observations obtained from the VZO (see Fig 3, for example). Sometimes observations do not fit into the framework of a given model. An example already mentioned is the 2-D-layered model for infiltration, which cannot explain the rapid saturation changes occurring at the water table. On the other hand, the behavior of a 3-D heterogeneous model with preferential pathways more closely resembles the saturation observations provided by ERT as well as the fundamentally different chemical transport observations provided by the tracer studies.

\section{Results \& Implications}

The Vadose Zone Observatory (VZO) at LLNL utilizes a variety of monitoring methods to track controlled infiltration experiments simulating leaks in underground tanks and plumbing. The unsaturated regime at the site is approximately 60-70 feet in thickness and consists of silt, silty-sand and silty-gravel deposits. Simulations of infiltration treating the deposits as layers, that is, neglecting the potential for a 3-D heterogeneous structure, suggest that the vadose zone will function as a formidable barrier to contamination of the water table by a near-surface leak. However, electric resistance tomography (ERT) carried out during infiltration experiments shows that the top and bottom of the unsaturated zone are in very good hydrologic communication. Following the initiation of a near-surface infiltration event, saturation changes are detected just above the water table within hours. Similar results are obtained from gypsum-block tensiometers placed at different levels in a nearby monitoring well. The ERT images of electrical conductivity changes suggest the formation initially of a plumelike structure in the vicinity of the injection point. Beneath this structure, what resembles a pathway or channel to the water table is rapidly formed. Yet the results of our attempts to track the migration of conservative chemical tracers such as deuterium show that the detection of saturation 
changes across the vadose zone cannot be equated with the arrival of significant levels of tracers at the water table. Except for a minor but potentially very significant exception, the arrival of tracers at the water table appears to be most closely related to the total volume of water injected into the soil at the leak point. For injected volumes less than some minimum value, significant volumes of tracer do not appear to reach the water table. This finding is consistent with the predictions of our numerical simulations. Overall, these results imply that the vadose zone can function as a site for long-term storage of liquid-phase contamination that is eventually available for gradual release into the water table as a result of precipitation and other surface infiltration events. Only sitespecific experiments like those performed at the VZO will provide DOE with the required contaminant flux estimates needed for Hanford, INEEL and other facilities where there is a need to determine the long-term impact of a severely contaminated vadose zone on the underlying saturated regime. The use of both ERT and chemical tracers at the VZO has allowed us to identify potential "fast track" behavior in the vadose zone. Knowledge of the presence of a fast track is important for understanding why trace amounts of contamination may be detected at the water table when other evidence suggests that the bulk of it is still bound up at a much higher level in the vadose regime. The distribution of cesium beneath the Hanford tanks in the vadose zone and at the water table may possibly be explained by the type of fast track behavior that is present at the VZO.

Regarding the possible role colloids in contaminant transport, we directly examined nearby, uncased monitoring wells for evidence of ground water seepage during one infiltration experiment. We found no evidence of seepage into the boreholes or flow along desiccation cracks that intersected the boreholes. This lack of saturated flow in cracks or very porous soils may represent a significant inhibition to colloidal transport. A preliminary and ongoing experiment to test the ability of the vadose zone to inhibit the transport of micron-sized colloids failed to detect them at the water table or at any monitoring level in the unsaturated regime. Finally, in addition to improving our understanding of transport processes in the vadose regime, infiltration experiments at the VZO are allowing researchers to improve geophysical and hydrologic techniques as monitoring tools by permitting simultaneous comparisons between methods. 


\section{Figures}

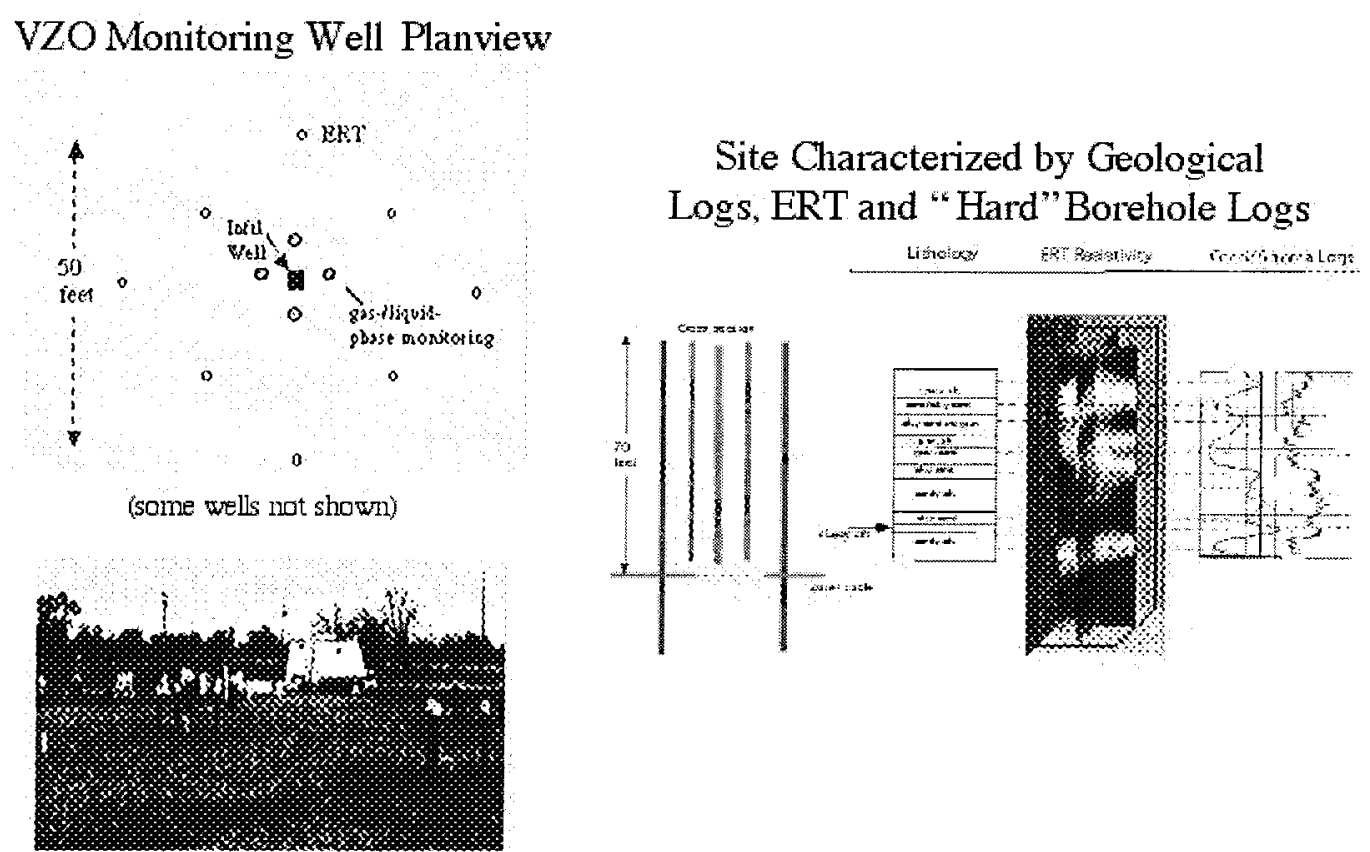

Figure 1.

The LLNL Vadose Zone Observatory developed with support from EMSP (54950) is a well-characterized site with approximately 20 wells containing instrumentation for measuring a variety parameters relevant to the migration of a plume from a shallow subsurface leak to the water table. Infiltration experiments simulating tank leaks are carried out at this site in a controlled, heavily monitored field environment. 

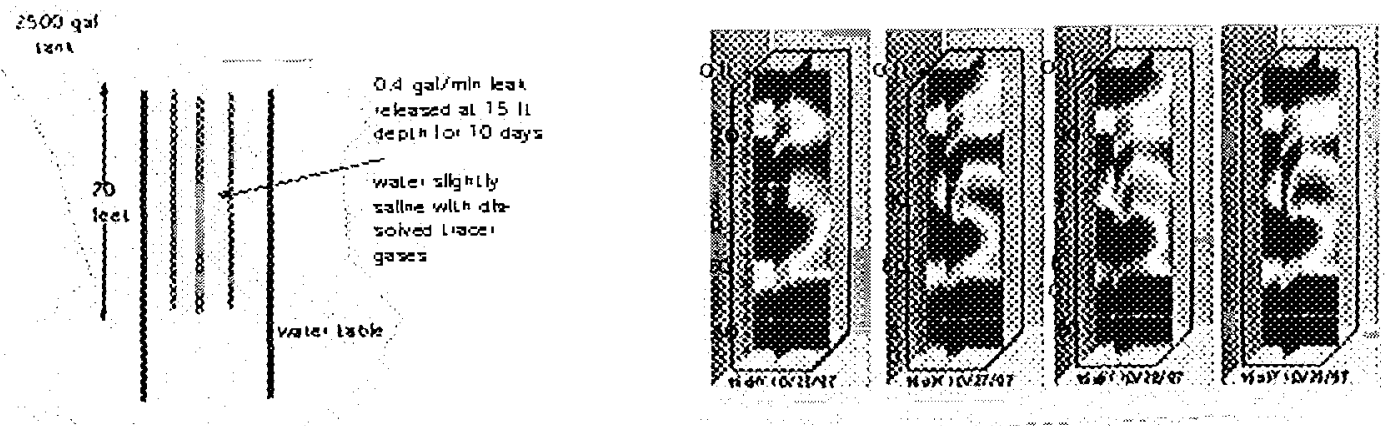

\section{Infiltration Parameters Monitored}

* Liquic phase location versus time (ERTtuacers)

* Gas phase location versus time (noble tracers)

* Gas-phase pressure at various depths

* Liquird phase saturation

* Gas \& liquid phase sampling

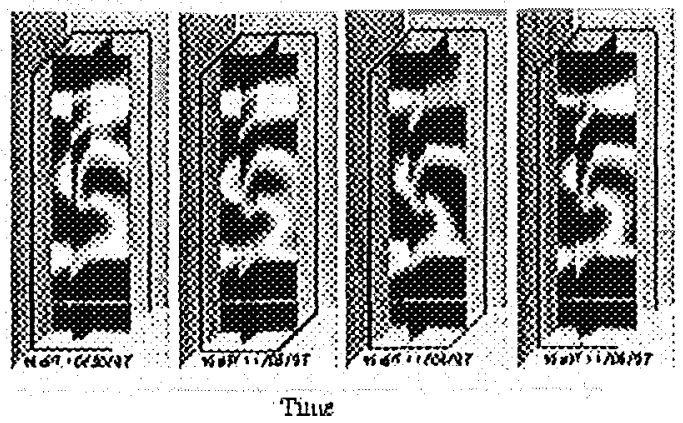

Figure 2

A schematic diagram (upper left) illustrates an infiltration event and the relationship of the infiltration plume to the ERT arrays shown in red. An actual sequence of ERT images is shown over approximately a 24 -hour period (right). The oscillation in color (green to blue to green) of the central kidney shaped image is evidently a response to the period voiding of trapped air in the vadose zone. The images that illustrate electrical conductivity change form rapidly down to the water table indicating the top and bottom of the vadose zone are well-connected hydraulically. 

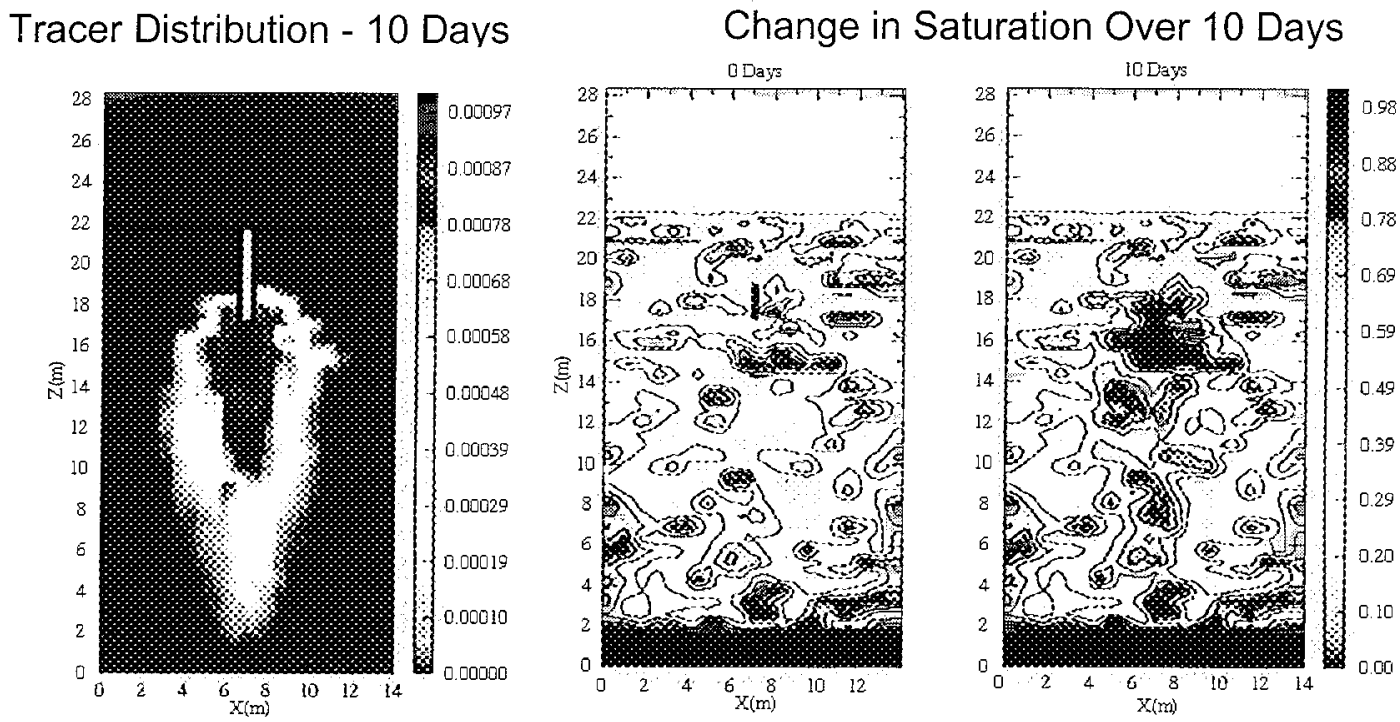

Figure 3.

A 3-D numerical simulation of infiltration at the VZO produces tracer arrivals at the water table that are in excellent agreement with the observations of tracer arrivals in terms of the total amount of water that must be infiltrated. The heterogeneous regime shown here produces results that more closely resemble the VZO observations than does a layered model with properties determined from core samples. 


\section{Bulk of tracer arrives more than}

\section{a month after release}

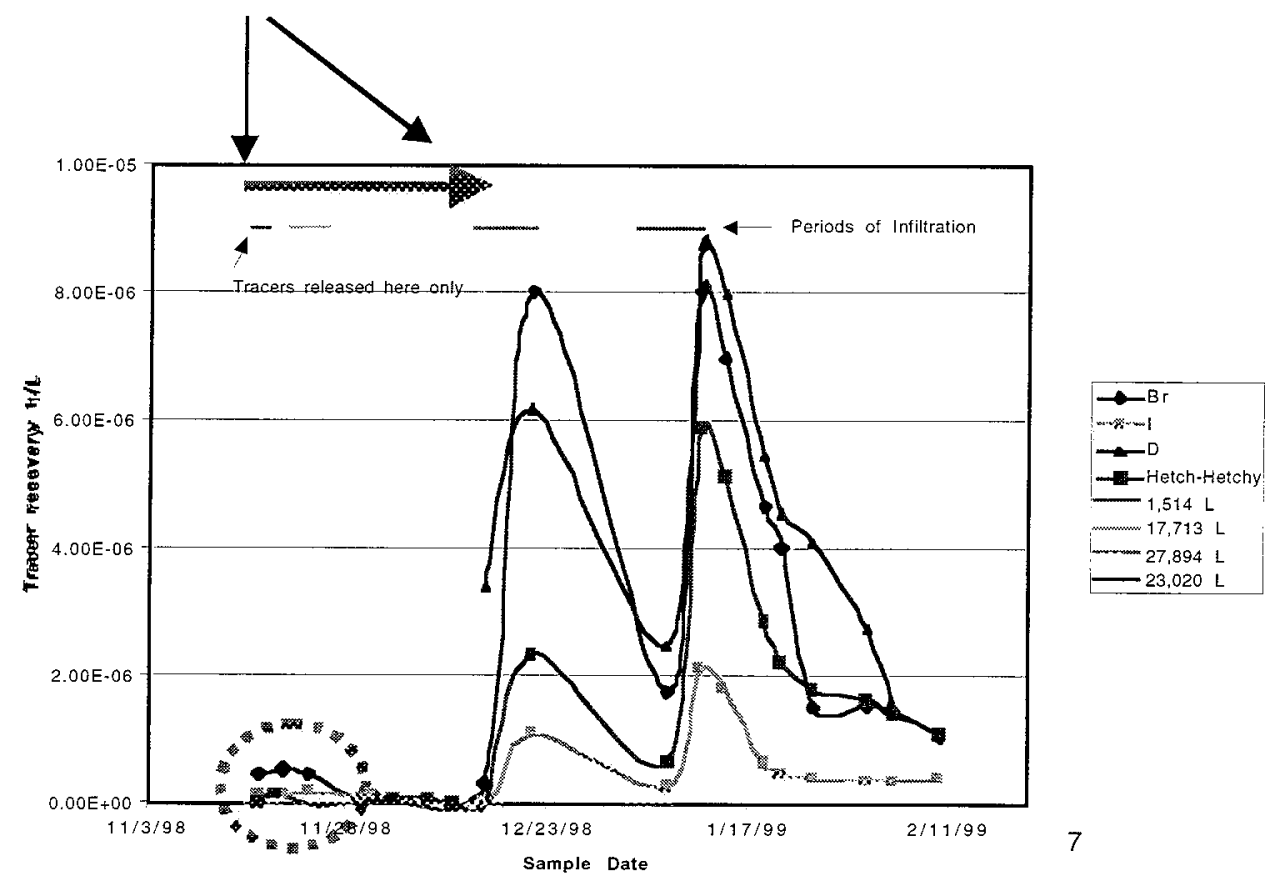

\section{Little bump in tracer concentrations occurs early on, but significant amounts of tracer do not arrive for more than a month}

\section{Figure 4.}

An a short-term infiltration event releasing about 1500 liters is indicated by the first red line (far left beneath large red arrow) indicating the period of infiltration occurring in early November 1998. Within the same day as the release, small amounts of tracer (see circled data) were evident at the water table. This suggests the presence of a "fast path" capable of moving at least a small amount of tracer to the water table. After the first initial 1500 l. injection of tracer-spiked water, fresh water was added in a series of three more experiments. The first large spike in tracer concentration occurs more than a month following the initial release and is consistent with modeling of infiltration carried out using the NUFT computer code. 


\section{Vadose Zone Observatory Salt Water Infiltration}

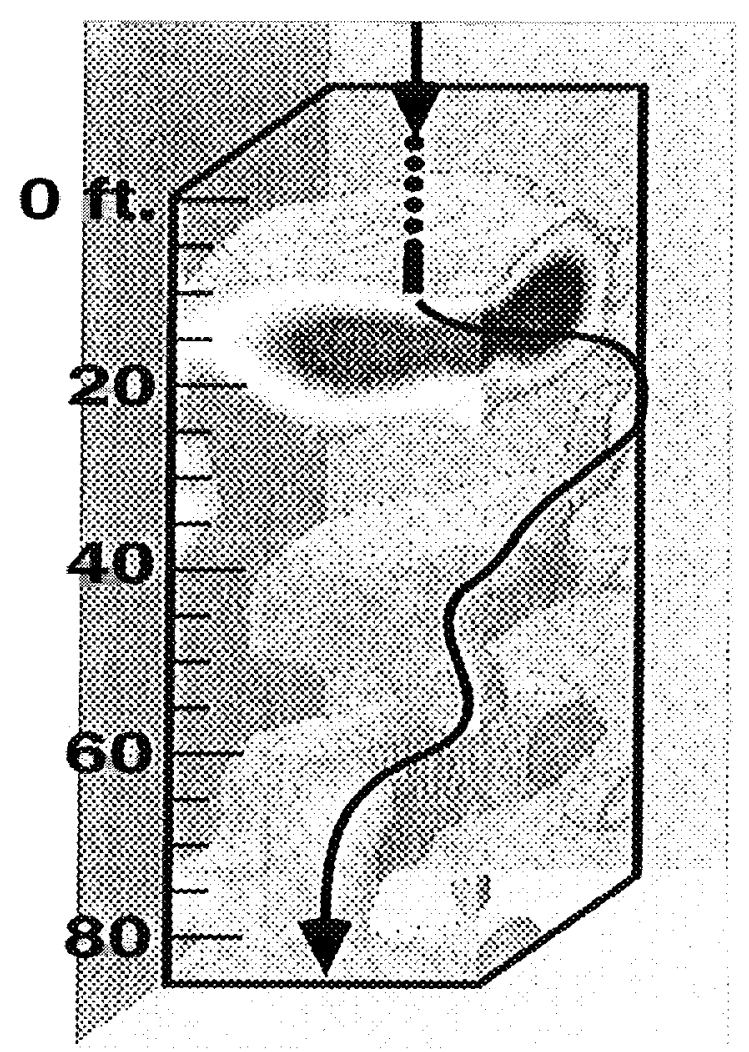

\section{Saturation Changes at bottom of VZ in less than 6 hours}

Figure 5.

An ERT image showing the electrical conductivity distribution less than 6 hours after a 1500 liter infiltration event using very saline water. The water table is normally below 65-70 feet but the salt water signal appears to have actually penetrated below the watertable owing to its greater density. This result in conjunction with the tracer study in Figure 3 strongly suggests that fast paths can carry at least part of the "contaminated" water rapidly to the water table. 


\section{Relevance, Impact and Technology Transfer}

This section addresses specific questions on relevance, impact, and technology transfer, in order to help DOE communicate project information to potential technology users, commercial partners, or sponsors of continuing research.

\section{a. How does this new scientific knowledge focus on critical DOE environmental management problems?}

A major goal of the DOE environmental monitoring and cleanup efforts is to be able to estimate the contaminant flux to the water table from a contaminated vadose zone on a site-by-site basis. To do this, it is necessary to understand the physics and chemistry of flow and transport in the vadose zone. The knowledge gained through our project contributes to understanding the response of the vadose zone to both contaminant inputs and subsequent infiltration events. We have also developed an approach that combines modeling, a high level of field monitoring and staged infiltration events to evaluate the hydrologic character of a particular site. Using this approach as well as the understanding provided by the field experiments carried out by this project, the major DOE goal of accurately estimating contaminant flux to the vadose zone at such locations as the Hanford cribs or tanks comes closer to reality. We very much want to engage DOE site managers in a dialog about our work because we think it is highly relevant to contamination transport issues that are of great concern to them.

b. How will the new scientific knowledge that is generated by this project improve technologies and cleanup approaches to significantly reduce future costs, schedules, and risks and meet DOE compliance requirements?

To do an efficient job of cleanup that translates into lower costs, it is first necessary to understand something about the site-specific vadose zone contamination problem. Field facilities, experiments and modeling of the sort developed in this project can provide a dynamic characterization of the response of a contaminated vadose zone to infiltration events in a way that 1-D/2-D modeling based only on the hydraulic properties of core samples has failed miserably to achieve. Once a suitable model is developed, estimates of contaminant fluxes to the vadose zone can be made with some confidence using the approach developed here. Based on estimates of contaminant flux to the water table, informed decisions that save money can be made about what if any action is needed to deal with the contaminated site.

c. To what extent does the new scientific knowledge bridge the gap between broad fundamental research that has wide-ranging applications and the timeliness to meet needs-driven applied technology development?

One result of this research is an improvement in the understanding of vadose zone processes that are important in developing better conceptual and ultimately numerical models of the response of particular contaminated vadose zone sites to leaks and 
rainwater infiltration. This information can be used now at facilities like Hanford in developing improved models of the flux of contamination through the vadose zone to the water table. Another result of this work involves the development/improvement of monitoring and imaging techniques and the associated diagnostic modeling used to interpret the results of the techniques. There is a great need to carry out this kind of work now at contaminated sites, but the approaches used here can be easily generalized to these sites. Again, a major goal of DOE is to estimate fluxes of contamination to the saturated zone on a site-by-site basis. All the work here contributes to that goal now.

\section{d. What is the project's impact on individuals, laboratories, departments, and institutions? Will results be used? If so, how will they be used, by whom, and when?}

The Vadose Zone Observatory developed under EMSP project \#54950 has hosted a number of visits from individuals affiliated with DOE - Richland, DOE-Oakland, Lawrence Berkeley Laboratory, INEEL, State of California, Electromagnetic Instruments Inc., Techniscan Inc. and other organizations. Owing to interest in the facility, a poster is available at the site to acquaint visitors to our facility with our work in this area. An additional sense of impact can be ascertained from proposed or funded studies that have used the VZO concept as a model. LBNL submitted an EMSP research proposal (unfunded) to do work at or near Hanford that was based on the VZO concept according to members of LBNL management. Proposed infiltration experiments at Hanford using the VZO concept were topics of discussion between LBNL and Hanford personnel. In a presentation, Phil Long of PNL proposed to the PI (Sept. '97) that he consider duplicating his facility on the Hanford Reservation. Currently, such infiltration experiments are being carried out at Hanford and similar infiltration experiments are being planned for INEEL. Charles Carrigan serves as a member of the Steering Committee for Hanford VZ Facility Experiments representing EMSP.

The VZO has been named a Soilbed test facility for the NSF sponsored Center for Subsurface Sensing and Imaging Systems (CenSSIS see www.censsis.neu.edu or http://www.numag.neu.edu/0011/censsis.html\#anchor5627340). CenSSIS was designated as an Engineering Research Center having the goal of enhancing the cross-disciplinary development of subsurface imaging techniques relevant to medical, ocean, industrial, and environmental applications. Following a major NSF site visit in February 2000 at Northeastern and Boston Universities, a one-day workshop, at which the VZO was featured, was devoted to the discussion of vadose zone environmental problems. Charles Carrigan, VZO principal investigator, recently (Nov 13,2000) gave an invited seminar for the annual CenSSIS Industrial Conference at Boston University on vadose zone contamination issues including the application of VZO techniques.

During more than one third of the project's tenure, the VZO was the focus of research by a part of an internship of the Defense Nuclear Facilities Safety Board (DNFSB). David Ralston, with a master's degree from Stanford, worked on a variety of VZO problems including barometric pumping as a mechanism for the transport of volatile subsurface contamination. He co-authored several conference presentations and is first author on a 
manuscript that will be submitted to a refereed journal. The following letter was sent to Charles Carrigan by John T. Conway, Chairman of DNFSB:

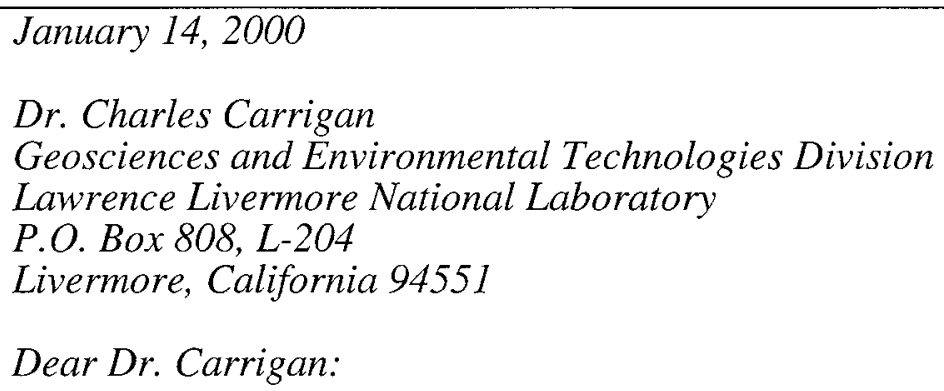

Sincerely,

John T. Conway

Chairman

cc: Mr. Michael K. Hooper

Dr. C. Bruce Tarter

Dr. Dennis K. Fisher

Dr. Leland W. Younker

Dr. Kenneth J. Jackson

In addition to David Ralston's research, some VZO experiments were carried out and analyzed by Dr. Brenda Ekwurzel who was a postdoctoral researcher at LLNL during the project. She also co-authored several presentations as well as an interview presentation on her VZO work that culminated in the award of a junior faculty position at the University of Arizona.

Results of this work have been presented at EM, Subsurface Contaminants Focus Area (SCFA Augusta, '99) and EMSP workshops (Chicago '98, Atlanta '00) and also at the Advanced Vadose Zone Characterization Workshop that was held in Richland, WA, Jan. 19-20, 2000, sponsored by the PNNL Hanford Groundwater/Vadose Zone Integration Project. A description of the VZO and associated work appears in a sidebar of the DOE sponsored book entitled "Vadose Zone, Science \& Technology Solutions", Battelle Press, 2000 .

An AGU special session on vadose zone transport organized by Charles Carrigan was held in May 1998 at the Boston meeting. Three presentations on VZO results were presented at that time. 
Finally, EMSP supported part of the research on forward modeling of electrical imaging methods and subsurface heating that received significant attention appearing as a cover article in Environmental Science \& Technology (November 15, 2000) (see cover below):

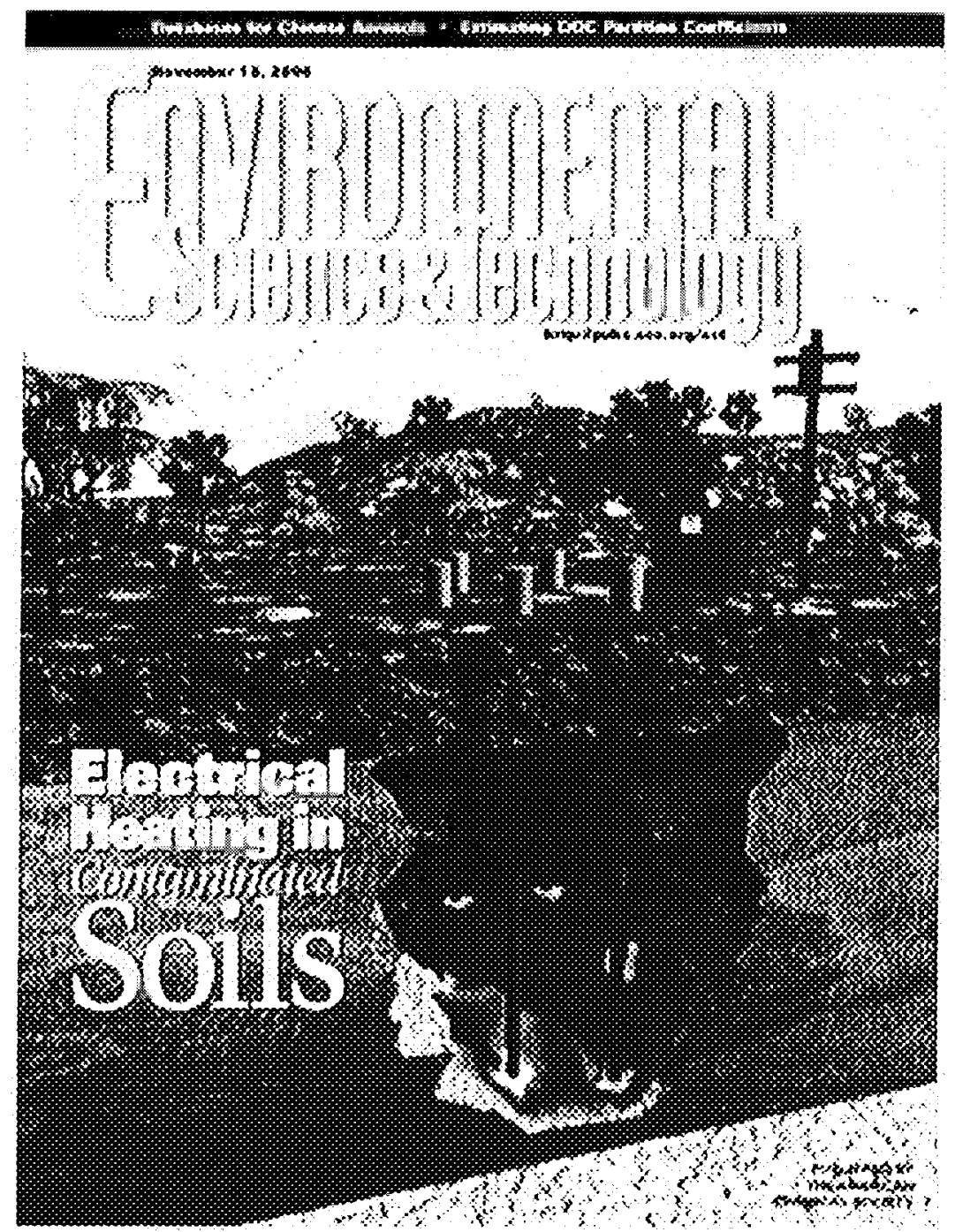

e. Are larger scale trials warranted? What difference has the project made? Now that the project is complete, what new capacity, equipment or expertise has been developed?

More trials or experiments using the VZO concept are warranted to investigate the effects of heterogeneous vadose regimes that differ from that hosting the VZO. The experiment is already intermediate in scale, and it is not clear that a larger version of the same thing is really required. The leaks simulated in the current VZO facility are comparable to what might be expected for a real leak at Hanford or at some other DOE facility. 
Regarding the difference that the project has made, it should be apparent from c. above that the impact on organizations, other labs and people has been significant. We have been contacted/visited by a number of DOE administrators and researchers. We continue to encourage collaborations with other DOE sites and remain available as a subsurface testbed for evaluating transport processes relevant to the EM cleanup effort. A lot of conceptual ideas/models of flow and transport need to be tested in other soil environments besides those of a few select sites at Hanford or INEEL if these ideas/models are going to have any generalized value to the DOE complex. The facility also remains available as a testbed for sensor and imaging development. The fact that this project received a high rating on relevance to DOE needs during the '99 EMSP competition, suggests that our facility offers potential that remains untapped by EM programs. There has been significantly more interest in real collaborations from CenSSIS and from NSF researchers who want to work with us on imaging, sensor development and data transmission and telemetry.

At LLNL the project has afforded technical staff to develop a very strong capability in vadose zone hydrology in addition to the Lab's continuing work in saturated zone hydrology. We also now have a facility (LLNL VZO) that can be used for basic research into vadose zone flow and transport, imaging, sensor development and other applied research projects.

Finally, the project also partially supported Boris Faybishenko and his group at LBL to develop a new combination lysimeter/tensiometer system. The equipment was tested at the VZO and a patent disclosure has been filed.

\section{f. How have the scientific capabilities of collaborating scientists been improved?}

This project involved numerous researchers (9) from LLNL who have improved their understanding of vadose zone processes as well as expertise in monitoring techniques. David Ralston participated in a 16 month internship (DNFSB Internship) that allowed him to participate in field experiments, do computer modeling, make a poster presentation and write the first draft of a manuscript for a journal. Brenda Ekwurzel spent part of her postdoctoral career at LLNL doing tracer studies at the VZO. She also made a poster presentation and is working on the first draft of a peer-reviewed research paper.

\section{g. How has this research advanced our understanding in the area?}

This work has enhanced understanding of vadose zone flow and transport processes as discussed in earlier sections of this report. We have developed a better sense of the relationship between contaminant storage and transport in the vadose zone as a result of our infiltration experiments and modeling. We are also improving our understanding of how subsurface Electric Resistance Tomographic images relate to actual flow and transport processes in the vadose zone. This represents a significant improvement in our interpretive abilities. 
h. What additional scientific or other hurdles must be overcome before the results of this project can be successfully applied to DOE Environmental Management problems?

We need to extend this work in the new EMSP project (\#70149) to further develop the relationships between tomographic imaging, hydrological properties and subsurface flow and transport processes. It is also necessary to develop a quantitative approach to enhancing (conditioning) simulations of infiltration events using both tomographic and standard hydrological point-measurement information.

i. Have any other government agencies or private enterprises expressed interest in the project?

Several private enterprises have expressed significant interest in this project and using our facility (VZO) as a testbed. They include:

Center for Subsurface Sensing \& Imaging Systems (CenSSIS) NSF Sponsored Northeastern University

Boston, MA

Michael Silevitch, Director

CenSSIS has requested to use our facility (VZO) as a soils imaging testbed for their subsurface imaging program

Qing H. Liu, Associate Professor NSF Sponsored

Duke University

Department of Electrical Engineering

130 Hudson Hall

Box 90291

Durham, NC 27708-0291

Professor Liu has proposed to use our facility for soil sensor and high-speed data transfer development purposes.

Electromagnetic Instruments (EMI) SBIR Sponsored

Emeryville, CA

Mike Wilt, V.P.

Techniscan, Inc.

Salt Lake City

Utah

Steve Johnson, President

Lt. Larry Cook \& Dennis Bernia

AFRL/MLQ (TRW)

Tyndall AFB FL 32403-5323 
Under an SBIR contact, EMI and Techniscan collaborated with us in carrying out an infiltration experiment to evaluate a new triaxial, twin receiver electromagnetic induction tomography (EMIT) borehole tool.

\section{Jim Lombard}

GeoSystems Analysis, Inc. 100 North Stone, Suite 907

Tucson, AZ 85701

Lombard is using subsurface barometric pressure fluctuations obtained from the VZO monitoring wells and stored in a monitoring database to use in his model for estimating subsurface soil permeabilities.

Boris Faybishenko

Earth Sciences Div

Lawrence Berkeley Lab

Berkeley, CA

Ernie Majers

Earth Sciences Div

Lawrence Berkeley Lab

Berkeley, CA

Faybishenko used our facility with support from us to test a new lysimeter/tensiometer apparatus that his laboratory produced. Majers used the VZO to evaluate cross borehole imaging capabilities of his radar system.

Some DOE Visitors to the VZO site:

DOE --Richland group

Ed Berkey, NETAC

Earl Mattson, INEEL

DOE --Oakland group 


\section{Personnel Supported}

This project provided varying degrees of support for a number of researchers at LLNL:

Charles Carrigan, Bryant Hudson, Abe Ramirez, Bill Daily, Mike Buettner, Jeanne Moran

LLNL technical support personnel were also partially supported (approximately .1 to .2 FTE level):

Stan Martins (Environmental Protection Div)

The project provided support (other than salary) to one post-doctoral researcher and one Defense Nuclear Facilities Safety Board Intern student at LLNL:

Brenda Ekwurzel

David Ralston 


\section{Publications / Abstracts}

Carrigan, C.R., Hudson, G.B., Ramirez A., Daily, B., Buettner, M., Martins, S., "Field and Modeling Investigations of Two-Phase Transport in a Heterogeneous Vadose Regime." Manuscript in preparation for submission to Water Resources Research, 2001.

Ralston, D. and Carrigan, C.R., Implications of topography and heterogeneity for barometrically induced gas-phase transport in the vadose zone, manuscript in preparation for Adv. In Water Res., 2001.

Carrigan, C.R. and Nitao, J.J., Predictive and diagnostic simulation of in situ electrical heating in contaminated, low-permeability soils, cover article for Environmental Science \& Technology, 34, 4835-4841, 2000.

Carrigan, C.R. (1999), Understanding The Fate And Transport Of Multiphase Fluid And Colloidal Contaminants In The Vadose Zone Using An Intermediate-Scale Field Experiment in EM sponsored book Vadose Zone, Science and Technology Solutions, Battelle Press, 2000.

Carrigan, C.R. (1999), Calibration And Testing Of Predictive Models Of Gas-Phase Transport In The Vadose Zone: An Example From The Nevada Test Site in EM sponsored book Vadose Zone, Science and Technology Solutions, Battelle Press, 2000.

Hudson, G.B., "Isotope Tracers for Tracking Groundwater Recharge." California Water Reuse Association, Artificial Water Recharge Workshop, Newport Beach, CA, April 5, 1997.

Hudson, G.B., "The Xe-124 Water Infiltration Experiment at Anaheim Lake." Santa Ana River Water Quality and Health Effects Study, Orange County Water District, Fountain Valley CA, June 10-11, 1997.

Carrigan, C.R., Hudson, G.B., Ramirez A., Daily, B., Buettner, M., Martins, S., "The Vadose Zone Observatory: Monitoring the Contaminant Fast Track to the Water Table." Presented to LLNL visiting Environmental Programs Science Advisory Committee (EPSAC), May 1998. (Presentation converted to LLNL Environmental Programs web page format.)

Carrigan, C.R. and G.B. Hudson (1998), Characterization of Contaminant Transport by Gravity, Capillarity and Barometric Pumping in Heterogeneous Vadose Regimes, Extended Abstract Volume (144), DOE/EMSP Program Review, Chicago, IL.

Carrigan, C.R. et al. (1998), The Vadose Zone Observatory: Dynamical Characterization of Liquid- and Gas-Phase Contaminant Transport in a Heterogeneous Soil Regime. Transactions of the AGU (EoS), 79, No. 45, F384. 
The following three abstracts are for presentations given in a special session (H-12) on vadose zone transport organized by C.R. Carrigan for the Spring Meeting of the American Geophysical Union, Boston, May 31-June 4, 1999.

Carrigan, C.R. et al. (1999), Lessons about Transport and Monitoring at the Vadose Zone Observatory at LLNL. Appeared Transactions of the AGU (EoS), Spring Meeting, Boston.

Ekwurzel, B. et al. (1999), Deuterium, Br, I, and ${ }^{18} \mathrm{O}$ Used as Tracers of Infiltration Water Movement Through the Vadose Zone. Appeared Transactions of the AGU (EoS), Spring Meeting, Boston.

Ralston, D.K. et al. (1999), Implications of Modeling for Gas-Phase Transport at the LLNL Vadose Zone Observatory. Appeared Transactions of the AGU (EoS), Spring Meeting, Boston. 


\section{Interactions}

\section{a. Participation/presentations at meetings, workshops, conferences, seminars}

Numerous presentations have been given at EMSP workshops/meetings at Hanford 1997, 98, 99 and 2000, EMSP Chicago 1998, EMSP Atlanta 2000, SCFA Augusta 1998, National Science Foundation Center for Subsurface Sensing and Imaging Systems (CenSSIS) in Boston, 1999 and 2000, etc. In addition, paper work presented at Fall AGU 1998 meeting and a special session on vadose zone hydrology was organized by Charles Carrigan for the Spring AGU 1998 Annual Meeting in Boston.

\section{b. Consultative and advisory functions to other laboratories and agencies}

C.R. Carrigan was invited to present results of this work at the Advanced Vadose Zone Characterization Workshop that was held in Richland, WA, Jan. 19-20, 2000, sponsored by the PNNL Hanford Groundwater/Vadose Zone Integration Project. The P.I. also served on the Nat. Workshop Tech. Prog. Committee, Environmental Management Science Program, DOE in 1999-2000 and as a member of the Steering Committee for Hanford VZ Facility Expts. representing EMSP, (2000). The PI also participated as a consultant in a one-day session on the vadose zone at Boston University in February 2000 .

\section{c. Collaborations}

Please refer to item (i) in section titled "Relevance, Impact \& Technology Transfer" for an extensive discussion. Additionally, interactions with P.I.'s on other EMSP projects, in particular projects that involve geophysical field measurements or techniques (e.g., Patricia Berge of LLNL and B. Faybishenko of LBNL) continue informally and may lead to future collaborations. 


\section{Transitions}

As noted above, our vadose zone experimental approach was incorporated into other proposals including ones relevant to the Hanford leaky tank scenario. The need to relate the electrical conductivity field with the flow and transport regime has been recognized and is being used to in part motivate the development of a new subsurface simulation capability that will allow more accurate quantification/simulation of contaminant transport to the water table. Again, this is a major goal of characterization at contaminated DOE sites.

\section{Future Work}

This project (54950) resulted in the development of the Vadose Zone Observatory that has become part of a newer EMSP project (70149) to elucidate the physics of flow and transport in the vadose zone and to develop improved methods of imaging contaminant transport in the subsurface.

\section{Literature Cited}

Carrigan, C.R. et al. (1998), The Vadose Zone Observatory: Dynamical Characterization of Liquid- and Gas-Phase Contaminant Transport. Transactions of the American Geophys. Union (Eos), 79, No. 45, F384. (See also http://www-ep.es.llnl.gov/www ep/esd/sstrans/Carrigan/Vadose/index.html)

Ekwurzel, B. et al. (1999), Deuterium, Br, I, and ${ }^{18} \mathrm{O}$ Used as Tracers of Infiltration Water Movement Through the Vadose Zone. In Transactions of the American Geophys. Union (Eos), 79. No. 45, May 1998.

McCarthy, J.F. et al. (1998), Colloid Transport and Retention in Fractured Deposits. EMSP Workshop Abstract Volume, \#143, Chicago, July 1998, p. 283.

Nitao, J. J. (1995), Reference manual for the NUFT flow and transport code, version 1.0, Lawrence Livermore National Laboratory Report (UCRL-ID-113520), Livermore, CA.

Ralston, D.K. et al. (1999), Implications of Modeling for Gas-Phase Transport at the LLNL Vadose Zone Observatory. To appear in Transactions of the American Geophys. Union (Eos). 